\title{
A Transition Arm Modular Multilevel Universal Pulse-Waveform Generator for Electroporation Applications
}

\author{
Mohamed A. Elgenedy, Student Member, IEEE, Ahmed Darwish, Shehab Ahmed, Senior Member, \\ IEEE, and Barry W. Williams
}

\begin{abstract}
High voltage (HV) pulses are used in electroporation to subject pulsed electric field (PEF) onto a sample under treatment. Pulse-waveform shape, voltage magnitude, pulse duration, and pulse repetition rate are the basic controllable variables required for particular PEF application. In practice, a custom-made pulse generator is dedicated for each PEF application with limited flexibility in changing these variables. In this paper, a universal pulse-waveform generator (UPG) is proposed, where the controller software-algorithm can manipulate a basic generated multilevel pulse-waveform to emulate many different PEF pulse-waveforms. The commonly used PEF HV pulse-waveforms can be generated as bipolar or monopolar with controllable pulse durations, repetition times, and voltage magnitudes. The UPG has the ability to generate multilevel pulses that have controllable $d v / d t$ which allow reduction of the electromagnetic interference (EMI) generated by the converter. The UPG topology is based on half-bridge modular multilevel converter (HB-MMC) cells forming two transition arms in conjunction with two bi-state arms, together creating an H-bridge. The HB-MMC cell-capacitors provide a controllable energy source which charge from the dc input supply and discharge across the load, while the two bi-state arms allow charging the HB-MMC cell-capacitors. Hence, the UPG topology offers modularity, redundancy, and scalability. The HB-MMC individual cell-capacitance is low and the cell-voltages are balanced by employing the sorting and rotating algorithm used in conventional HB-MMC topologies for HVDC transmission applications. The viability of the proposed UPG converter is validated by MATLAB/Simulink simulation and scaled-down experimentation.
\end{abstract}

Index terms-Electroporation, high-voltage, modular multilevel converters (MMC), pulsed electric field, pulsewaveforms generator, transition arm, series connected IGBTs.

Manuscript received April 16, 2016; and accepted January 3, 2017. This work was supported by a National Priorities Research Program (NPRP) grant NPRP (7-203-2-097) from the Qatar National Research Fund (QNRF).

M. A. Elgenedy is with the Department of Electronic and Electrical Engineering, University of Strathclyde, G1 1RD Glasgow, U.K., and also with the Electrical Engineering Department, Faculty of Engineering, Alexandria University, Alexandria 21544, Egypt (e-mail: mohamed.elgenedy (a) strath.ac.uk)

A. Darwish, and B. W. Williams are with the Department of Electronic and Electrical Engineering, University of Strathclyde, Glasgow G1 1XQ, U.K. (email:ahmed.mohamed-darwish-badawy@strath.ac.uk

barry.williams@strath.ac.uk).

S. Ahmed is with the Department of Electrical and Computer Engineering,

Texas A\&M University at Qatar, Doha 23874, Qatar (e-mail: shehab.ahmed@qatar.tamu.edu).

\section{INTRODUCTION}

$\mathrm{E}$ LECTROPORATION is the process where a biological cell-membrane is exposed to a specific pulsed electric field (PEF) [1]. Depending on the biological cell characteristics, a suitable PEF can be applied for electroporation [2]. Typically, there are two types of electroporation, namely: reversible and irreversible. In reversible electroporation, the cell-membrane survives after the electroporation process. This is required, for example, when inserting protein cells in the cell-membrane [3]. However, death of the microorganism's cell is associated with irreversible electroporation [3]. Water treatment, air pollution control, and food sterilization are examples where irreversible electroporation is exploited for either decontamination or sterilization from bacteria and harmful microorganisms using PEF [4]-[7].

Generating the electroporation pulses is primarily controlled by the applied high voltage (HV) across the cell-membrane, pulse-waveform shape, and pulse application time. Therefore, there is a wide range of pulses, where a specific pulse suites a specific application. Accordingly, the voltage magnitude can be in the kilo-volt range (1-100 kV) while the pulse duration ranges between nanoseconds and milliseconds [8]. Generally, the higher the voltage, the shorter the pulse duration.

Among the wide range of possible HV pulse-waveforms for electroporation; rectangular, exponential, and combined narrow and wide pulse duration pulses are commonly used, as shown in Fig. 1 [8]. The HV pulses can be either monopolar or bipolar as shown in Fig. 1. The rectangular pulses, Figs. 1a and $1 \mathrm{~d}$, and the exponential pulses, Figs. $1 \mathrm{~b}$ and $1 \mathrm{e}$, are usually applied in water and air disinfection applications [9]. The pulses of combined narrow and wide pulse durations, shown in Figs.1c and 1f, are recently proposed in [1], [5] and [10] and are preferred in safe food sterilization, without altering the food nutrition values and freshness quality [11][12].

Marx generators, pulse forming networks, and Blumlein lines are commonly used classical generators to generate electroporation HV pulses [13]-[15]. However, with ongoing HV semi-conductor switch development (in silicon and silicon carbide), mainly increased voltage rating and high switching frequency capability, it is possible to generate the necessary HV pulses via power-electronics based converters [16]. 


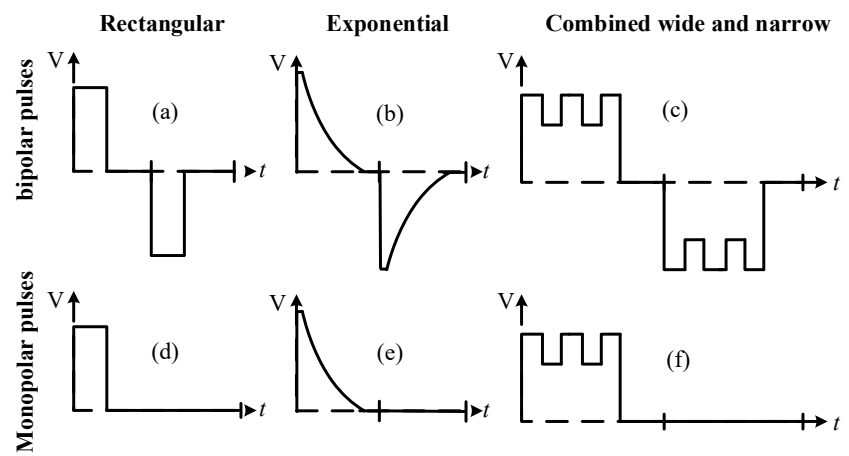

Fig. 1. Commonly used pulse-waveforms in electroporation.

In a solid-state Marx generator, as an example, the semiconductor switches operate to control the charging and discharging of its capacitors such that they charge in parallel then discharge in series across the load [17]-[19]. The modular buck-boost converters in [20] generate HV pulses with proper turn ON/OFF operation of the semiconductor switches. Halfbridge modular multilevel converter (HB-MMC) cells are used in [21] to generate HV pulses from a low-voltage supply by charging the cell-capacitors sequentially, which are then discharged in series across the load. Modified HB-MMC cells are used in [22]-[23], as one phase-leg of the three-phase HBMMC topologies used for HVDC application, to generate HV pulses from a HV dc supply. A series diode between adjacent cells modification affords sensorless operation of the MMC cell-voltages, when employing a specific ON/OFF switching sequence.

Neither classical nor modern semiconductor based pulse generators can generate different pulse-waveforms when utilizing one converter topology. Therefore, usually, there is a specific pulse generator for every associated PEF application, to generate its required pulses. Also, for a given pulsewaveform, some generators can only generate either monopolar or bipolar polarity pulses [24]. Series-connected $\mathrm{HV}$ switches for chopping the HV dc-voltage to form the pulses, adopted in [18], [19] and [25] for example, are evident. Similarly, in [21] HV series-connected diodes are required to bypass the load during cell-capacitor charging.

This paper proposes a universal HV pulse-generator (UPG) fed from HV dc-supply, $V_{s}$, where the UPG is based on series connected HB-MMC cells forming two transition arms and two bi-state arms, together forming an $\mathrm{H}$-bridge. The transition arm cell-capacitors provide a controllable energy source which allow multilevel voltage transitions. The bi-state arms, facilitate the charging of the HB-MMC cell-capacitors in the transition arms from $V_{s}$ after discharging across the load. The transition arm concept was introduced in [26] for dual active bridge (DAB) application in HVDC transmission, in which the transition arm allow multilevel voltage transition between positive and negative voltage rails creating a quasi two-level voltage waveform with reduced $d v / d t$ in order to reduce the voltage stresses on the $\mathrm{DAB}$ ac transformer. However, in this paper the two transition arms are utilized to build bipolar multilevel pulse waveforms such that one arm allow multilevel voltage transition between 0 and $+V_{s}$ while the multilevel voltage transition in the other arm is between 0 and $-V_{s}$.

Without changing any physical connections, by only changing the controller software algorithm, the UPG is able to generate a multilevel pulse waveform that has controlled $d v$ / $d t$ which allow reduction of the electromagnetic interference (EMI) generated by the converter [27]. Such a feature allows the generation of the basic HV pulses namely: rectangular, exponential as well as combined narrow and wide pulsewaveforms. Also, not only can bipolar or monopolar pulses be generated, but pulse-waveforms with special characteristics are also possible. For example, the proposed topology facilitates changing the duration of a particular polarity or merging both polarities null durations. Therefore, the UPG can be used in both reversible and irreversible electroporation applications.

Utilizing the HB-MMC cells and the bi-state arms in the UPG affords output flexibility by software control, along with hardware modularity, scalability, and redundancy. Each UPG HB-MMC cell-capacitance is low, which dramatically reduces converter cost, footprint and weight. Individual cell-voltages are balanced with the conventional sorting algorithm used in HB-MMC topologies for HVDC transmission applications, where cell-capacitors are continuously rotated and sequenced based on measurement of their individual voltage [28]-[29]. Although, each bi-state arm is formed by a series connection of IGBTs, the IGBTs are turned ON/OFF only when the voltage across the arm is zero, ZVS (or, near to zero). Transitional voltage sharing occurs with zero IGBT current, thus voltage sharing normally associated with hard switched series connected semiconductors, is not an issue.

The proposed UPG converter is introduced in section II and its operation principle outlined in section III. Its analysis and parameters selection are given in section IV, simulation and experimental results are present in sections $\mathrm{V}$ and VI respectively, and the proposed UPG topology variations and limitations are discussed in VII.

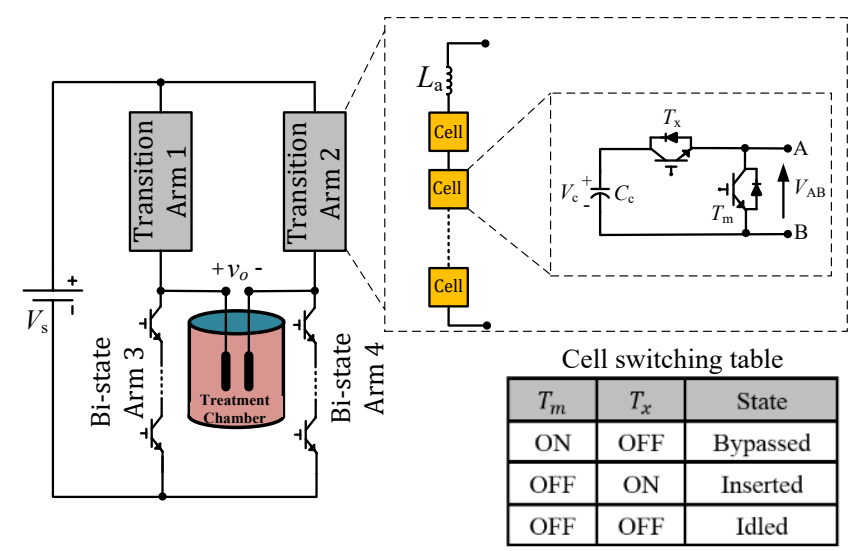

Fig. 2. The proposed UPG converter topology. 


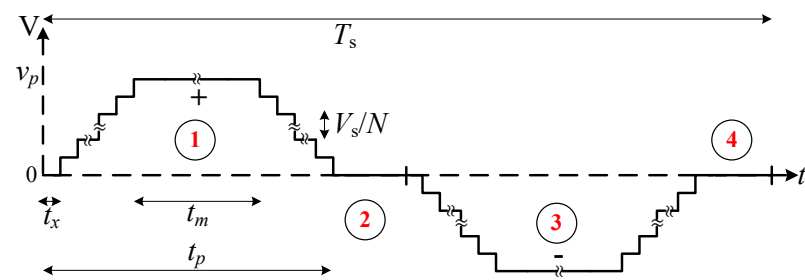

Fig. 3. UPG basic multilevel pulse-waveform, where $N t_{x} \ll t_{m}$.

\section{UPG CONVERTER TOPOLOGY}

The proposed UPG converter topology is shown in Fig. 2. It consists of four arms forming an H-bridge, the two upper arms, Arm1 and Arm2, are the transition arms formed of $N$ series connected HB-MMC cells while the two lower arms, Arm3 and Arm4, are the bi-state arms formed of series connected IGBT switches. Each transition arm has a small arm series inductor $L_{a}$ to supress the inrush current between cellcapacitors during their insertion process and to allow cell capacitor charging when connected to the dc input supply $V_{s}$.

Any HB-MMC cell of the transition arms has a capacitor $C_{c}$ in series with an auxiliary IGBT switch/diode $T_{x}$ and both are paralleled to a main IGBT switch/diode $T_{m}$, as shown in Fig. 2. Each cell can operate in any of three switch states; bypass, insertion and idle, as shown in Fig. 2. The bypass state (when the main IGBT is ON and the auxiliary IGBT is OFF) implies that the cell is a short circuit and the voltage across the cell terminal $V_{A B}$ is near zero. The insertion state (when the main IGBT is OFF and the auxiliary IGBT is ON) connects the cellcapacitor to $V_{A B}$, hence, the cell-voltage is $V_{A B}=V_{c}$. The idle state (when both the main and auxiliary IGBTs are OFF) introduces an open circuit across the cell terminal at steadystate, thus, hindering the current flow through the arm from the dc-link. Therefore, the two transition arms have tri-state modes. Since the two lower arms are formed from series connected IGBTs, they can operate only in bi-state modes (either turned $\mathrm{ON}$ or $\mathrm{OFF}$ ).

For proper UPG converter operation, each arm must be able to withstand the dc-link voltage $V_{S}$. Consequently, the voltage of the HB-MMC cell-capacitors in the transition arm should be balanced and each cell-voltage fluctuates around $V_{s} / N$. The MMC sorting and rotating technique in [28] is adopted. Therefore, each cell-voltage is continuously measured, compared with other cell-voltages in that corresponding arm, and the capacitor voltages are sorted. Accordingly, the highest voltage capacitor among the available capacitors is inserted first at each voltage level during the transition from 0 to $\pm V_{s}$, while the lowest cell-voltage is bypassed first during the transition from $\pm V_{S}$ to 0 .

The UPG basic multilevel pulse-waveform $V_{p}$ is shown in Fig. 3, and can be defined by four sequential intervals: positive pulse, positive null, negative pulse, and negative null, respectively. Controlling the five parameters defining this basic waveform allows the generation of any desired pulsewaveform, like the waveforms in Fig. 1. The five parameters are: repetition time $T_{s}$, total pulse time $t_{p}$, pulse plateau time $t_{m}$, cell-voltage step $V_{s} / N$, and step voltage-level applied time $t_{x}$. Accordingly, there are $N+1$ voltage levels from the zero-voltage-level to the peak pulse voltage $V_{s}$ (neglecting IGBT ON resistances, diode voltage drops and arm inductor resistance). The positive and the positive null intervals in the UPG basic waveform (regions 1 and 2 in Fig. 3, respectively) can be expressed mathematically as in (1):

$$
v_{p}=\left\{\begin{array}{cr}
\sum_{n=1}^{N} \frac{n V_{s}}{N}, & 0 \leq t<N t_{x} \\
V_{s}, & N t_{x} \leq t<\left(N t_{x}+t_{m}\right) \\
\sum_{n=1}^{N}\left(V_{s}-\frac{n V_{s}}{N}\right), & \left(N t_{x}+t_{m}\right) \leq t<t_{p} \\
0, & t_{p} \leq t<1 / 2 T_{s}
\end{array}\right.
$$

Mathematically, region 3 is the negative equivalent of region 1 , while region 4 is similar to region 2 . Accordingly, Table I defines the emulated pulse-waveforms of Fig. 1 generated by the UPG from its basic pulse-waveform controlling attributes.

TABLE I

GENERATION OF DIFFERENT PULSE-WAVEFORMS FROM THE BASIC UPG MULTILEVEL PULSE-WAVEFORM

\begin{tabular}{|l|l|l|}
\hline \multicolumn{2}{|c|}{ Controlling attributes } \\
\hline
\end{tabular}

\section{UPG OPERATION PRINCIPLE}

The UPG generated pulse-waveforms, are normally bipolar, where the HB-MMC cells in Arm2 are responsible of generating the positive pulse-duration, while the HB-MMC cells in Arm1 are responsible for generating the negative-pulse duration. Disabling a specific transition arm will lead to generating monopolar pulse-waveforms with the desired polarity.

As discussed, there are four intervals for a bipolar pulsewaveform generation cycle. The operation for each interval is shown in Table II and can be explained as: during the positive pulse generation interval, the two bi-state arms are OFF, transition Arm1 cells are bypassed and transition Arm2 cells are inserted. 
TABLE II

OPERATING PRINCIPLE OF THE UPG

\begin{tabular}{|l|l|l|}
\hline & \multicolumn{1}{c|}{ Sequence of operation } \\
\hline
\end{tabular}

Consequently, the equivalent series connected capacitor $C_{c} / n$ is inserted across the load producing a voltage of $+n V_{S} / N$, where $n$ is the number of the inserted cells. Similarly, for negative pulse generation, again the two bi-state arms are OFF, transition Arm 2 cells are bypassed and transition Arm1 cells are inserted. Hence, the series connected capacitor $C_{c} / n$ is inserted across the load producing voltage $-n V_{s} / N$. During the null intervals, Arm2 or Arm1, for positive or negative pulses respectively, cell-capacitors are charged from the dclink supply, while the load voltage is nullified. Thus, the equivalent inserted capacitor $C_{c} / N$ charges to $V_{s}$. Turning $\mathrm{ON} / \mathrm{OFF}$ the bi-state arms is assured soft-switching operation, ZVS (that is, the series-connected switches are switched only when the voltage across the arm is near zero). After the positive/negative pulse interval, charging of Arm2/Arm1 is the next interval which requires turning $\mathrm{ON}$ the bi-state Arm4/Arm3.

Thus, during charging of one of the transition arms, the other transition arm is idled, and the charging cell-capacitors are inserted. Therefore, the voltage across the corresponding bi-state arm remains close to zero, hence it can be turned ON allowing the input supply to charge the cells. During the charging interval, the charging transition arm voltage reaches the supply voltage $V_{S}$, hence, the voltage difference across the corresponding bi-state arm is zero, and therefore, the bi-state arm can be turned OFF, in a ZVS state.

Idling one transition arm during the null intervals (or, the charging interval of the other transition arms) will not prevent charging its capacitor-cells, through $T_{x}$ diode, when starting the converter. At steady-state, the idled arm cell-capacitor voltages are charged to the supply voltage $V_{s}$, and since they are not participating in the pulse generation, the arm voltage will not change, hence the idled arm can be viewed as an open circuit during charging of the other transition arm, as shown in Table II.

\section{PARAMETERS SELECTION OF THE UPG}

Since bipolar rectangular pulse-waveform represents the case where all the cell-capacitors in the transition arms (Arm1 and Arm2) are to be inserted, giving a step from the zero voltage-level to the $\pm V_{s}$ voltage-levels, its generation will be considered in the following analysis and cell-capacitor sizing. In this paper, $\mathrm{HV}$ pulses with pulse durations of microseconds or longer are considered, hence, the PEF load is modeled as a resistive load, $R[4]$ and [30].

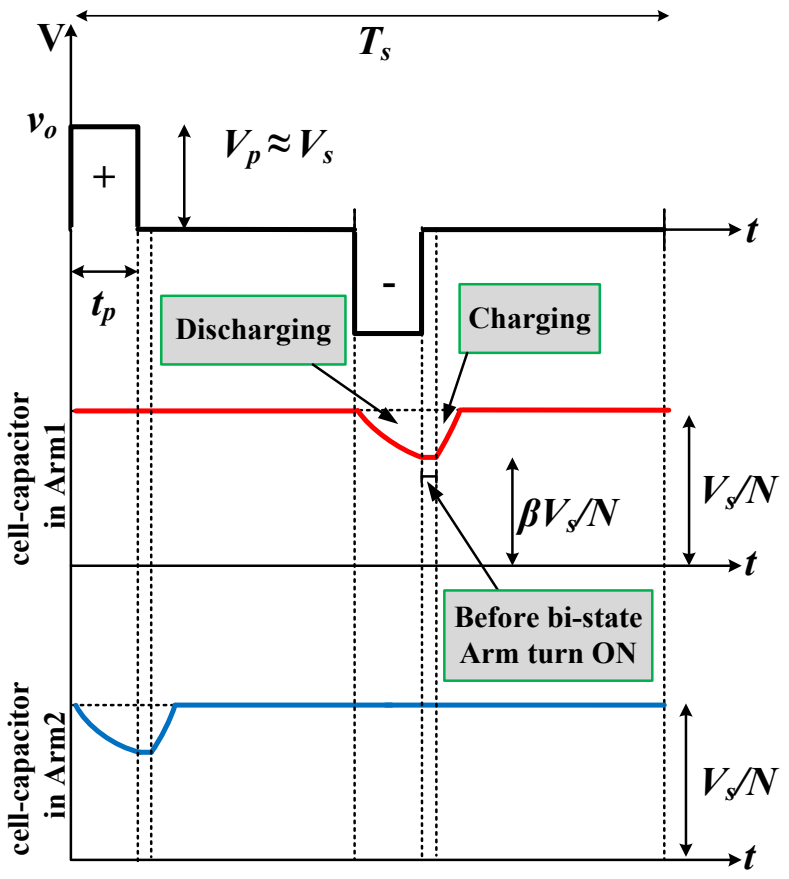

Fig. 4. Individual cell-capacitors of Arm1 and Arm2 charging and discharging sequence for generating a rectangular bipolar pulse. 
The UPG operation for each pulse polarity can be illustrated from an energy conversion perspective. Assume the individual cell-capacitors are pre-charged to $V_{S} / N$. During the positive pulse interval some of the energy stored in Arm2 capacitors is transferred to the load during pulse generation time $t_{p}$. Hence, Arm2 capacitors partially discharge and their voltage reduced accordingly. This energy reduction is compensated by recharging Arm2 individual cell-capacitors to $V_{S} / N$ during the positive-null interval. These two processes are illustrated in Fig. 4. The same procedures occur during the negative-pulse interval through Arm1 cell-capacitors. Therefore, the energy is transferred from the input dc supply to the load in two stages, first the input dc supply charges the corresponding cellcapacitors then the charged cell-capacitors partially discharge into the load. The energy transferred to the load $E_{L}$ during the pulse time is

$$
E_{L}=P_{L} t_{p}
$$

where $P_{L}$ is the power consumed by the load $R$ during pulse time $t_{p}$ which can be expressed as,

$$
P_{L}=\frac{V_{o}^{2}}{R}
$$

where $V_{o}$ is the load rms voltage which can be calculated from Fig. 4 as

$$
V_{o}=\sqrt{\frac{1}{T_{s}} \int_{0}^{T_{S}} v_{o}^{2}(t) d t}
$$

thus,

$$
V_{o}=\sqrt{\frac{2 t_{p}}{T_{s}}} V_{p}
$$

Neglecting IGBT voltage drops and the internal resistance of $L_{a}$, then $V_{p} \cong V_{s}$, hence, the load energy per pulse polarity is

$$
E_{L}=\frac{t_{p}^{2} V_{s}^{2}}{T_{S} R}
$$

The energy transferred to the load is equal to the difference between the initial energy stored in the individual arm capacitors $\left(E_{\text {cell }}^{i}=1 / 2 C_{c} \frac{V_{s}^{2}}{N^{2}}\right)$ and the energy remaining after the pulse $\left(E_{c e l l}^{p}=1 / 2 C_{c} \frac{\beta^{2} V_{s}^{2}}{N^{2}}\right)$. This energy can be estimated as

hence,

$$
\Delta E_{\text {cell }}=E_{\text {cell }}^{i}-E_{\text {cell }}^{p}
$$

$$
\Delta E_{\text {cell }}=1 / 2 C_{c} \frac{V_{s}^{2}}{N^{2}}-1 / 2 C_{c} \frac{\beta^{2} V_{s}^{2}}{N^{2}}
$$

where $\Delta E_{\text {cell }}$ is the energy difference in the individual cellcapacitor in the discharging arm, and the cell-voltage after discharge is expressed as a per unit, $\beta$, in terms of the initial cell-voltage $V_{S} / N$ as shown in Fig. 4. Thus the energy difference in the discharging transition arm of $N$ series cells is

$$
\Delta E_{\text {Arm }}=N \times \Delta E_{\text {cell }}=1 / 2 C_{c} \frac{\left(1-\beta^{2}\right) V_{s}^{2}}{N}
$$

where $\Delta E_{A r m}$ is the energy difference in the arm corresponding to a specific pulse polarity. Neglecting semiconductor losses, then $\Delta E_{A r m}=E_{L}$, hence the cell-capacitance is

$$
C_{c}=\frac{2 t_{p}^{2} N}{\left(1-\beta^{2}\right) T_{s} R}
$$

Denoting $\delta=t_{p} / T_{s}$, the pulse on-state duty ratio, (10) yields

$$
C_{c}=\frac{2 N \delta t_{p}}{\left(1-\beta^{2}\right) R} \alpha
$$

where $\alpha>1$ is a safety factor to account for neglected losses. $C_{c}$ can be tailored to produce an acceptable pulse droop for a given load and pulse characteristic (increase $C_{c}$ to decrease the voltage droop). The cell-capacitor per unit voltage droop, $(1-\beta)$, specifies the efficiency of the resonate recharging of the cell-capacitors. The resonant losses, related to the throughput power, are approximately the per unit droop, squared, viz. $(1-\beta)^{2}$. For example, with $10 \%$ capacitor voltage droop, the recharging losses are $1 \%$ the average power of the pulse causing the droop. These losses are dissipated in the charging circuit resistance and the bi-state arm devices as on-state losses. These device losses are mitigated by the fact that the bi-state arm devices do not incur switching losses; their switching is at zero voltage, ZVS.

Consequently, the total average power $P_{\text {tot }}$ associated with the applied HV pulses with repetition frequency $f_{s}$, can be calculated as (12) for bipolar pulses, while the value is halved for monopolar pulses.

$$
P_{t o t}=\frac{2 t_{p}^{2} V_{s}^{2}}{R} f_{s}^{2}
$$

The arm inductor $L_{a}$ in series with the MMC cells in HVDC applications has two functions; suppressing the circulating current in the cells and limiting the dc short circuit current [29]. Although, the proposed UPG converter topology adopts the technology of an MMC-HVDC converter, the operating principle is different, and dc-link short circuit blocking is not applicable. But, small arm inductance is preferred in each transition arm (Arm1 and Arm2) such that the inrush current is suppressed when inserting the cells in series across the load during discharging or across the de supply during charging. Additionally, resonance between $L_{a}$ and the arm capacitors should be avoided [30]. Hence, the device switching frequency should be well away from the resonance frequency of the equivalent $L C$ circuit to avoid exciting resonance currents. Therefore, based on the designed equivalent arm capacitance and repetition time, an estimation of the inductance of $L_{a}$ is

$$
L_{a}<\frac{N T_{s}^{2}}{4 \pi^{2} C_{c}}
$$

\section{Simulation Results}

The proposed UPG is assessed using MATLAB/Simulink simulations, with the parameters in Table III. The cellcapacitance $C_{c}$ is calculated based on (11), while (13) is used to estimate the arm inductance $L_{a}$. The number of the IGBT switches in bi-state arms, Arm3 and Arm4, is $N=10$. The simulations assess the ability of the UPG to mimic the commonly used pulse-waveforms in PEF applications and the flexibility of the converter to control the generated pulse attributes via the controller software-algorithm, without any physical changes to the power topology or the load connection. 
TABLE III

SIMULATION SPECIFICATION

\begin{tabular}{|l|c|c|}
\hline DC input voltage & $V_{s}$ & $10 \mathrm{kV}$ \\
\hline Number of cells/arm & $N$ & 10 \\
\hline Repetition time & $T_{s}$ & $200 \mu \mathrm{s}$ \\
\hline Arm inductance and resistance & $L_{a}, r_{a}$ & $2 \mu \mathrm{H}, 0.1 \Omega$ \\
\hline Arm resistance & $R_{a}$ & $0.1 \Omega$ \\
\hline Load resistance & $R$ & $1 \mathrm{k} \Omega$ \\
\hline Cell-capacitance & $C_{c}$ & $5 \mu \mathrm{F}$ \\
\hline Per unit remaining capacitor voltage & $\beta$ & 0.95 \\
\hline Safety factor & $\alpha$ & 2 \\
\hline
\end{tabular}

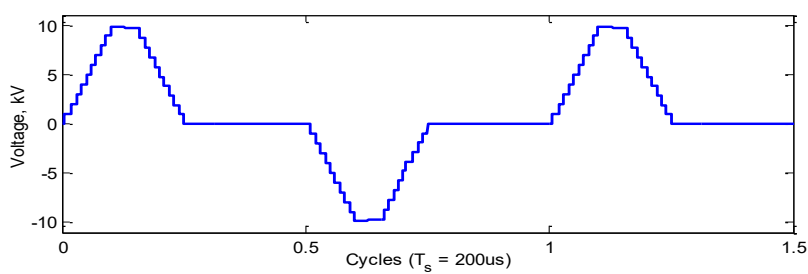

(a)

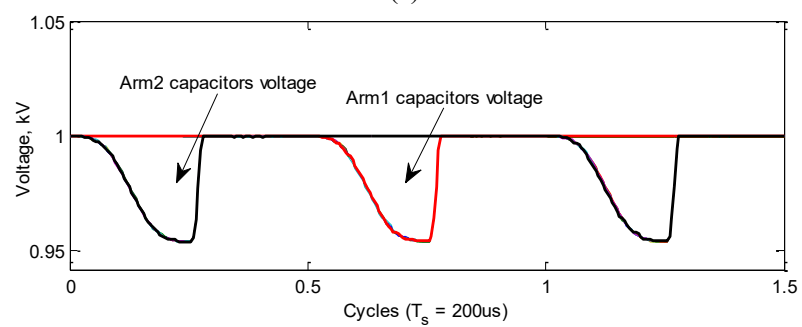

(b)

Fig. 5. Simulation of basic UPG multilevel pulse-waveform: (a) output bipolar HV pulses and (b) Arm1 and Arm2 capacitor voltages.

With a repetition frequency of $5 \mathrm{kHz}$, the basic UPG multilevel pulse-waveform is shown in Fig. 5. Fig. 5a shows the generated voltage pulse with $t_{x}=2 \mu \mathrm{s}, t_{m}=14 \mu \mathrm{s}$ and $t_{p}=50 \mu \mathrm{s}$. The cell-voltages of Arm1 and Arm2 are shown in Fig. 5b. In Fig. 5b, Arm2 contributes to the positive pulse generation while Arm1 contributes to the negative pulse generation. The cell-capacitors charge to the $1 \mathrm{kV}$ after their voltage decreases during discharge across the load. The voltage across and the current through the bi-state arm Arm4 during one cycle of pulse generation is shown in Fig. 6. In Fig. $6 \mathrm{~b}$ when the voltage across Arm4 is near zero, the bi-state arm switches are turned ON allowing capacitor charging current to flow. After the cell-capacitors are charged, the current reaches zero and the voltage across the bi-state arm is zero, hence, the arm switches can be turned OFF. During negative pulse generation, the bi-state arm is maintained OFF and the voltage across it is $V_{S}$ as shown in Fig. 6a.

Fig. 7a shows the generation of positive monopolar multilevel pulse-waveform, while the negative counterpart is depicted in Fig. 7b. Since the two transition arms can operate independently, not only a certain polarity can be omitted, but it can be generated with different characteristics. For example in Fig. 8a, the positive pulse is generated with $t_{x}=2 \mu \mathrm{s}, t_{m}=$ $24 \mu \mathrm{s}$ and $t_{p}=60 \mu \mathrm{s}$ while the negative pulse is generated with $t_{x}=2 \mu \mathrm{s}, t_{m}=2 \mu \mathrm{s}$ and $t_{p}=38 \mu \mathrm{s}$. Since the positive pulse duration is longer, the decrease in the cell voltages of Arm2 is more than those for Arm1, see Fig. 8b.
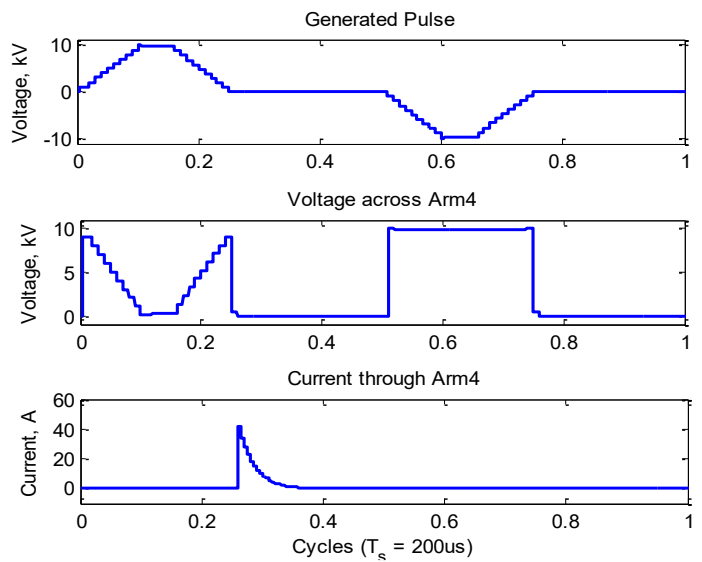

(a)
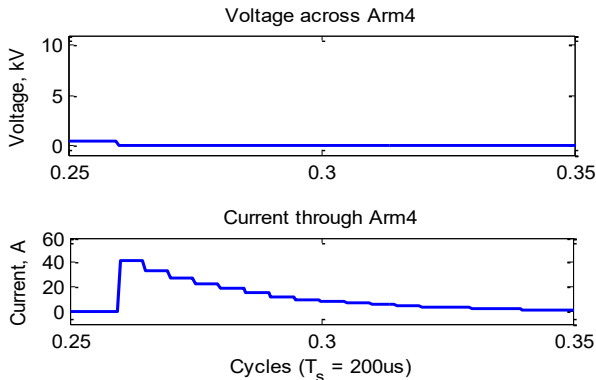

(b)

Fig. 6. Voltage across and current through bi-state Arm4 during positive pulse generation via Arm2 cell-capacitors (a) during one complete pulse cycle and (b) zoomed view of Arm4 voltage and current during Arm2 capacitors re-charging.

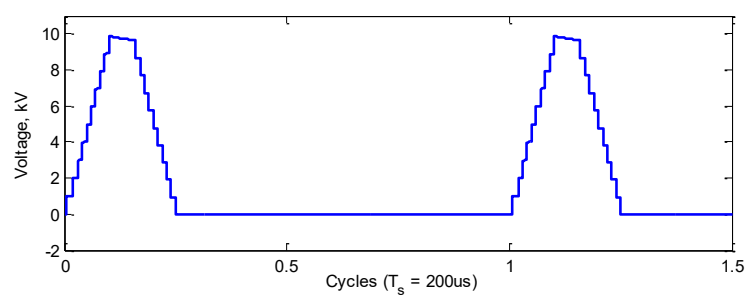

(a)

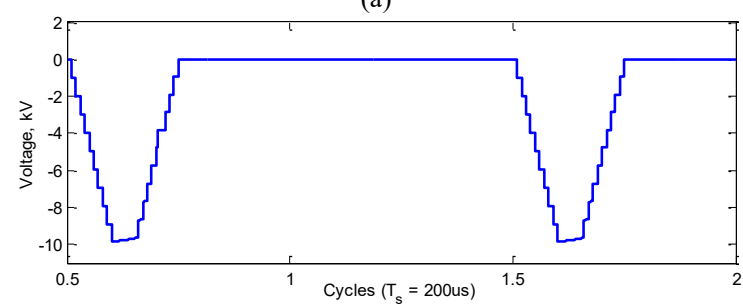

(b)

Fig. 7. Simulation of monopolar UPG multilevel pulses: (a) positive and (b) negative. 


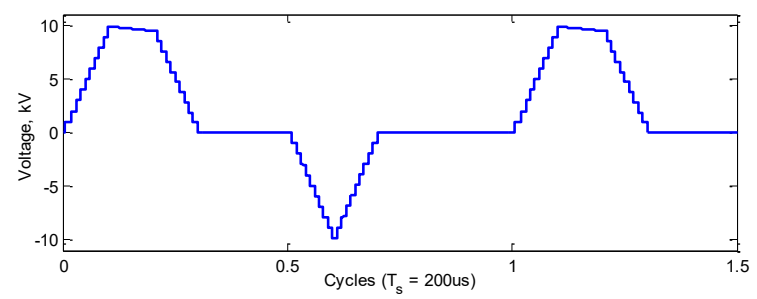

(a)

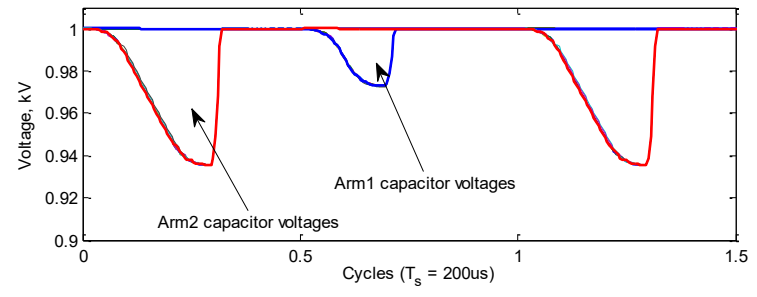

(b)

Fig. 8. Simulation of asymmetric bipolar UPG multilevel pulses: (a) output bipolar HV pulses and (b) Arm1 and Arm2 capacitor voltages.

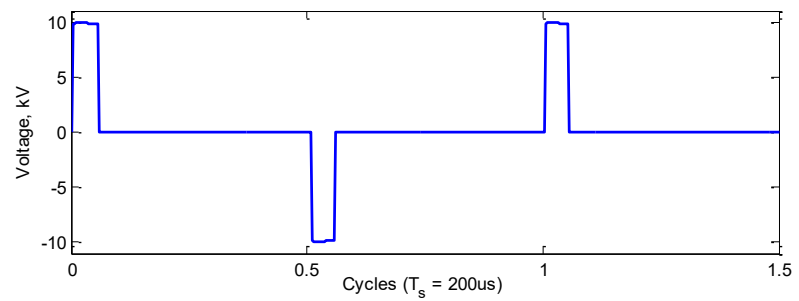

(a)

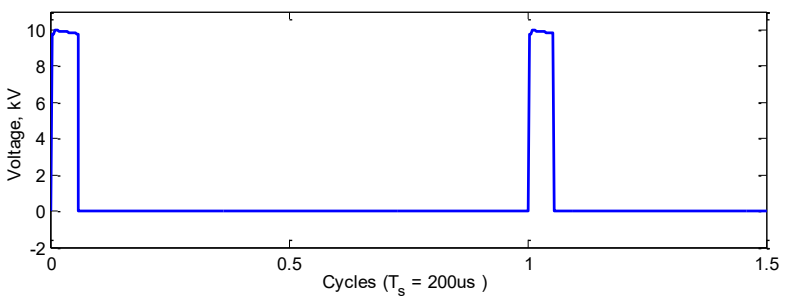

(b)

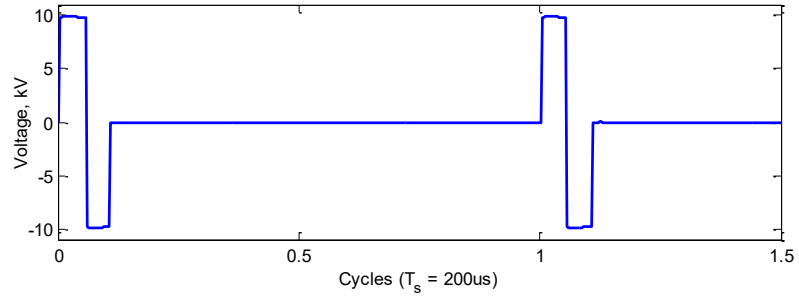

(c)

Fig. 9. Simulation of UPG rectangular output HV pulses: (a) bipolar, (b) positive monopolar and (c) combined null durations.

By setting $t_{x}=0$ and $t_{m}=t_{p}=10 \mu \mathrm{s}$, in the controller software, a rectangular pulse can be generated. The simulation results of bipolar rectangular pulses are shown in Fig. 9a. Generating positive monopolar and combined null duration rectangular pulses is explored in Figs. $9 b$ and 9c, respectively, with positive and negative pulse durations of $10 \mu$ s.

The features of controlled $d v / d t$ in the basic generated multilevel pulse waveform and the conventional rectangular pulse waveform can be combined as shown in Figs 10a and $10 \mathrm{~b}$ with repetition frequency of $10 \mathrm{kHz}$. The exploitable lower value of $t_{x}$ is limited by switching device turn $\mathrm{ON}$ and
OFF delay times. In Fig. 10a the $t_{x}$ value is $0.1 \mu$ s (viable with $\mathrm{SiC} 1700 \mathrm{~V}, 45 \mathrm{~m} \Omega$ MOSFETs, with $50 \mathrm{~ns}$ turn ON and OFF delays) while $t_{m}$ is $5 \mu \mathrm{s}$, hence the total rise time is much shorter than the plateau time. If a faster rise time is required, grouping of the cells can be employed. As shown in Fig. 10b, to achieve a rise time of $0.3 \mu$ s the ten cells are voltage sorted into three groups, two groups of 3 cells and one group of 4 cells.

Employing the flexibility afforded by the generated basic multilevel pulse-waveform from the UPG allows generating both exponential as well as combined wide and narrow pulsewaveforms. Such waveforms can be generated with either bipolar or monopolar polarities. With $t_{x}=2 \mu \mathrm{s}, t_{m}=10 \mu \mathrm{s}$, Fig. 11a shows bipolar exponential pulses and Fig. 11b shows positive monopolar exponential pulses. Consequently, with $m=5$ and $t_{x}=10 \mu \mathrm{s}$, bipolar combined wide and narrow pulses are shown in Fig. 12a and the negative monopolar version is shown in Fig. 12b.

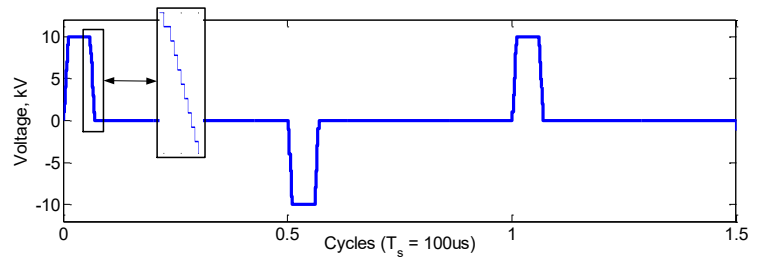

(a)

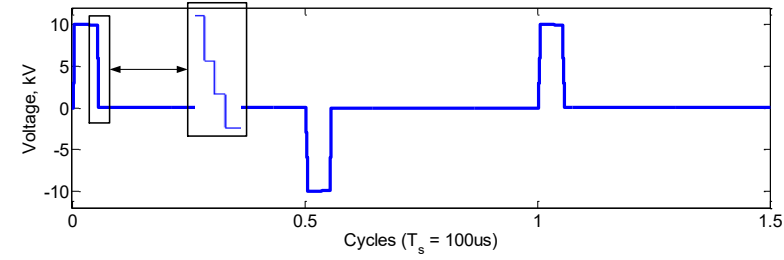

(b)

Fig. 10. Simulation of UPG $10 \mathrm{kHz}$ multilevel rectangular HV pulses with $t_{x}=0.1 \mu \mathrm{s}$ and $t_{m}=5 \mu \mathrm{s}$ : (a) without cells grouping and (b) with cells grouping.

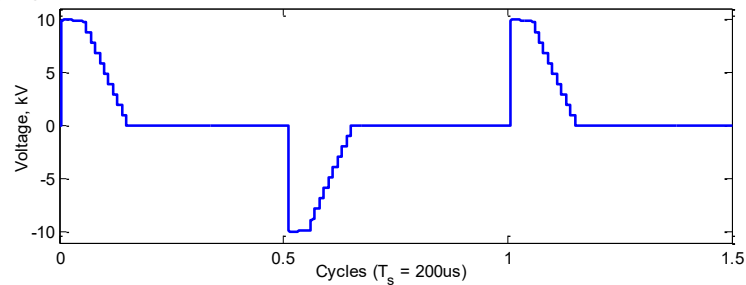

(a)

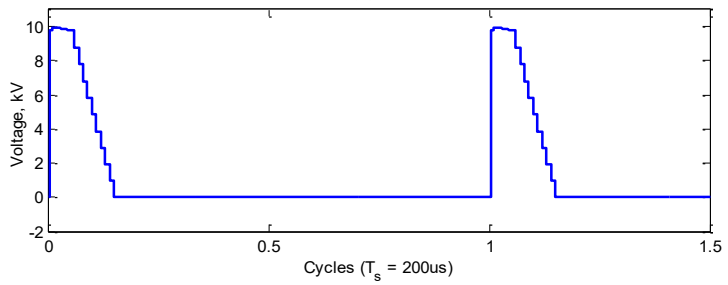

(b)

Fig. 11. Simulation of UPG exponential HV pulses with $t_{x}=2 \mu \mathrm{s}$ and $t_{m}=$ $10 \mu \mathrm{s}$ : (a) bipolar and (b) positive monopolar. 


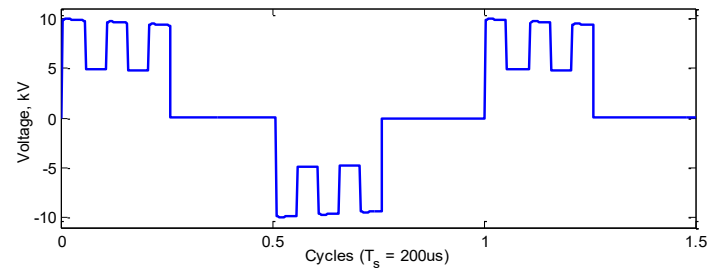

(a)

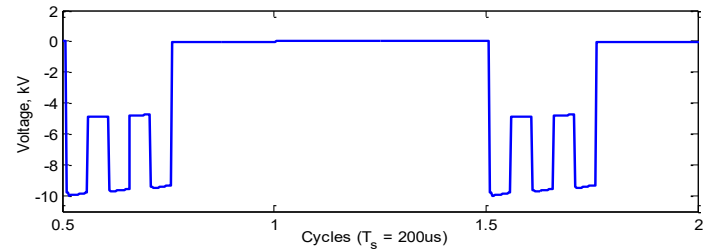

(b)

Fig. 12. Simulation of UPG combined wide and narrow HV pulses with $m=$ 5 and $t_{x}=10 \mu$ s: (a) bipolar and (b) negative monopolar.

\section{EXPERIMENTAL RESULTS}

The scaled-down UPG power circuit from Fig. 2 uses IGBT switches (STGW30NC60WD) for the HB-MMC arms which have antiparallel diodes, while the bi-state arms use Infineon IGW60T120 IGBTs. The control algorithm is implemented in eZDSP, which is a digital signal processor (DSP) board based on the Texas Instruments TMS320F28335 DSP, to generate the required gating signals for the UPG switches in the four arms. The experimental specifications are given in Table IV, and the scaled-down experimental rig is shown in Fig. 13. The experimentally generated four-level basic multilevel pulsewaveform is shown in Fig. 14. The output voltage pulses are shown in Fig. 14a with $t_{x}=20 \mu \mathrm{s}, t_{m}=40 \mu \mathrm{s}$ and $t_{p}=$ $120 \mu \mathrm{s}$, whereas a cell-capacitor voltage from Arm1 and Arm2 are presented in Fig. 14b. Since the input supply voltage is $150 \mathrm{~V}$, the cell-capacitors are charged to $50 \mathrm{~V}$, then during the associated pulse time the corresponding transition arm capacitors discharge across the load reducing the cellcapacitors voltage to $44 \mathrm{~V}$. Fig. 15 shows the waveforms of voltage across and the current through the bi-state arm Arm4 during a complete cycle of the generated pulse. The waveforms reveal that the bi-state arm is turned ON/OFF only when the voltage across the arm is near-zero, ZVS. With $t_{x}=$ $20 \mu \mathrm{s}, t_{m}=40 \mu \mathrm{s}$ and $t_{p}=120 \mu \mathrm{s}$ negative plus positive monopolar four-level voltage pulses are shown in Figs. 16a and $16 \mathrm{~b}$, respectively.

TABLE IV

EXPERIMENTAL SPECIFICATION

\begin{tabular}{|l|c|c|}
\hline DC input voltage & $V_{s}$ & $150 \mathrm{~V}$ \\
\hline Number of cells/arm & $N$ & 3 \\
\hline Repetition frequency for bipolar pulses & $1 / T_{s}$ & $1.8 \mathrm{kHz}$ \\
\hline Repetition frequency for monopolar pulses & $1 / T_{s}$ & $3.6 \mathrm{kHz}$ \\
\hline Arm inductance and resistance & $L_{a}, r_{a}$ & $1 \mu \mathrm{H}, 0.2 \Omega$ \\
\hline Load resistance & $R$ & $100 \Omega$ \\
\hline Cell-capacitance & $C_{c}$ & $15 \mu \mathrm{F}$ \\
\hline Per unit remaining capacitor voltage & $\beta$ & 0.9 \\
\hline Safety factor & $\alpha$ & 2 \\
\hline
\end{tabular}

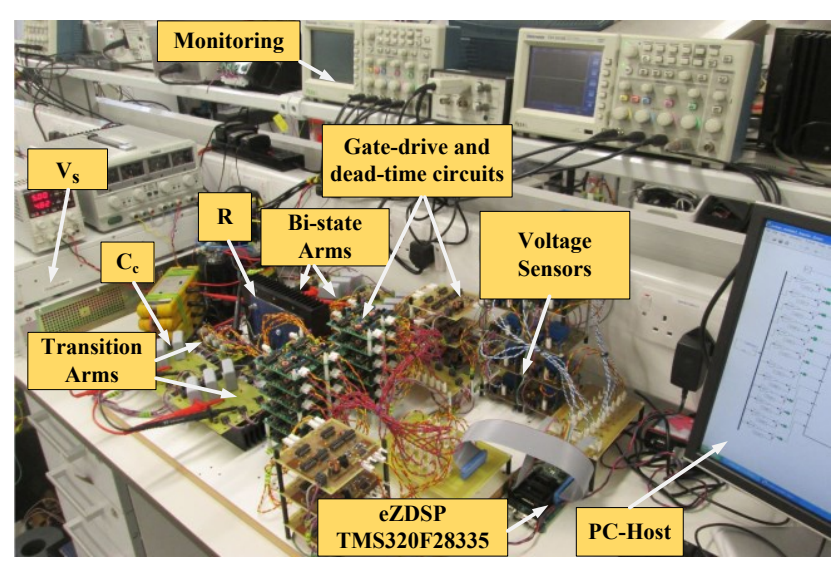

Fig. 13. Scaled-down experimental test rig.

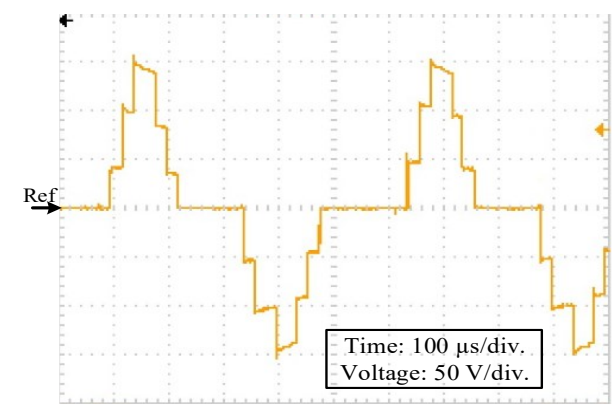

(a)

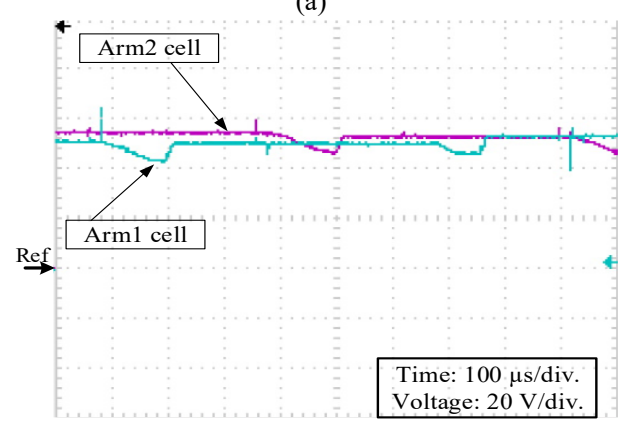

(b)

Fig. 14. Experimental results for UPG four-level bipolar pulses with a $50 \mathrm{~V}$ level: (a) output pulses and (b) a cell-capacitor voltage in the 2 transition arms.

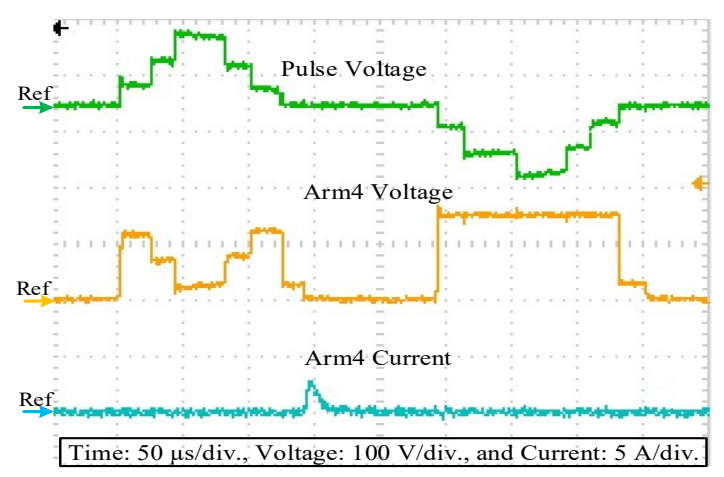

Fig. 15. Voltage across and current through bi-state Arm4 during complete cycle of pulse generation via Arm2 cell-capacitors. 


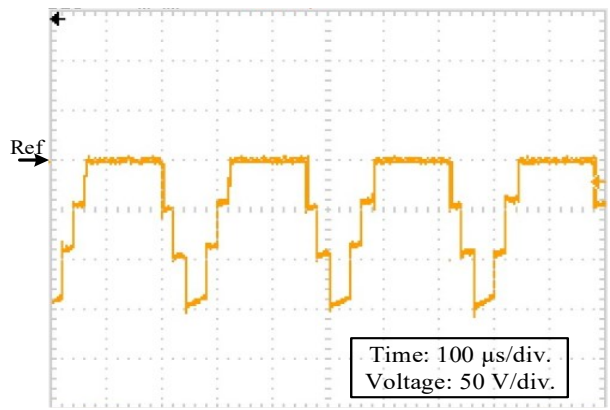

(a)

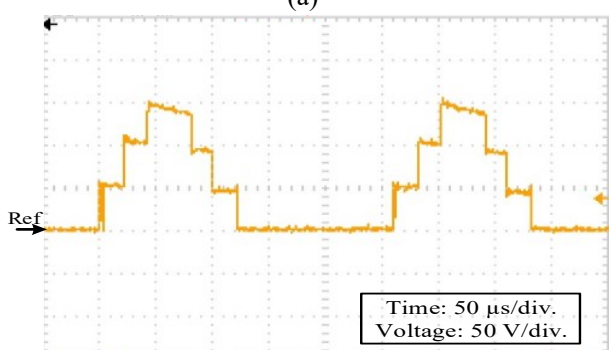

(b)

Fig. 16. Experimental results for UPG four-level monopolar pulses with a $50 \mathrm{~V}$ level: (a) negative and (b) positive.

Generating rectangular pulses with different characteristics is explored in Fig. 17. Symmetrical rectangular bipolar pulses with $t_{m}=20 \mu \mathrm{s}$ are shown in Fig. $17 \mathrm{a}$, whereas a cellcapacitor voltage from Arm1 and Arm2 are presented in Fig. 17b. Positive monopolar pulses with $t_{m}=40 \mu$ s are shown in Fig. $17 \mathrm{c}$, while combined null-durations pulses are illustrates in Fig. 17d.

Asymmetric rectangular pulse generation is shown in Figs. $18 \mathrm{a}$ and $18 \mathrm{~b}$. Fig. 18a shows a $40 \mu$ s rectangular positive pulse followed by a $20 \mu$ s negative pulse. An asymmetric combined null-durations rectangular pulse is depicted in Fig. $18 \mathrm{~b}$ with pulse times of $20 \mu \mathrm{s}$ and $40 \mu \mathrm{s}$, positive and negative respectively.

Bipolar exponential pulses with $t_{x}=20 \mu \mathrm{s}$ and $t_{m}=40 \mu \mathrm{s}$ are shown in Fig. 19a and a cell-capacitor voltage in the 2 transition arms are shown in Fig. 19b. While the monopolar version is shown in Fig. 19c. The combined wide and narrow pulses with $m=2$ and $t_{x}=20 \mu$ s are shown in Figs. 20a, 20b and $20 \mathrm{c}$ for bipolar pulses, its cell-capacitors voltage in the 2 transition arms, and its monopolar version of pulses, respectively.

Finally, to explore the validity of the concept in generating wide range of pulses, a bipolar rectangular pulse of duration of $4 \mu \mathrm{s}$ is generated with repetition rate of $10 \mathrm{kHz}$ and voltage of $0.6 \mathrm{kV}$ peak-peak as shown in Fig. 21.

It should be noted that, the series connected IGBTs in the bi-state arms, although in an OFF-state during rail-to-rail transitions, require shunt connected voltage sharing resistors and parallel capacitors to account for static leakage and output capacitance variation between series devices.

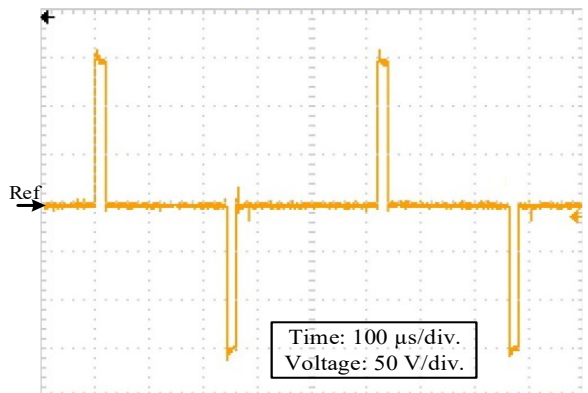

(a)

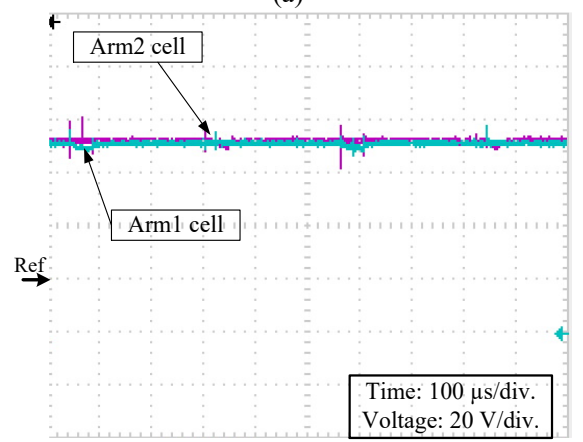

(b)

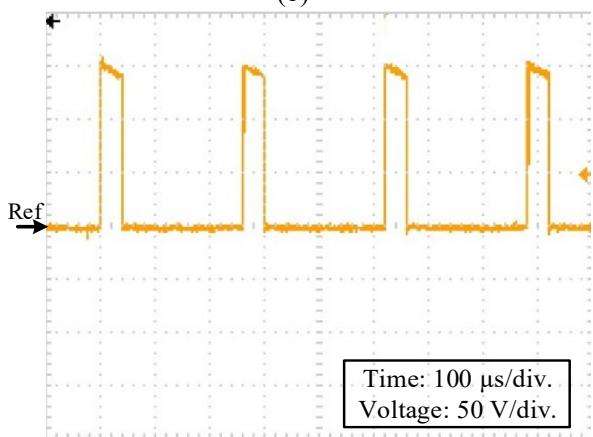

(c)

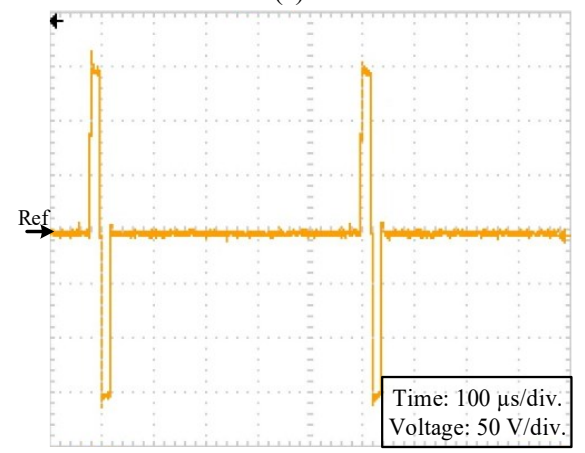

(d)

Fig. 17. Experimental results for UPG symmetrical rectangular pulses: (a) bipolar with $t_{m}=20 \mu \mathrm{s}$, (b) a cell-capacitor voltage in the 2 transition arms (c) positive monopolar with $t_{m}=40 \mu \mathrm{s}$ and (d) combined null durations with $t_{m}=20 \mu \mathrm{s}$. 


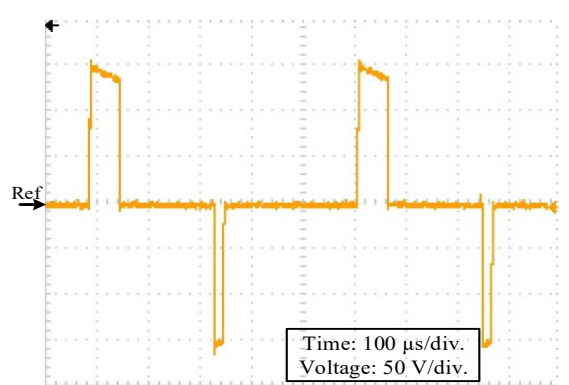

(a)

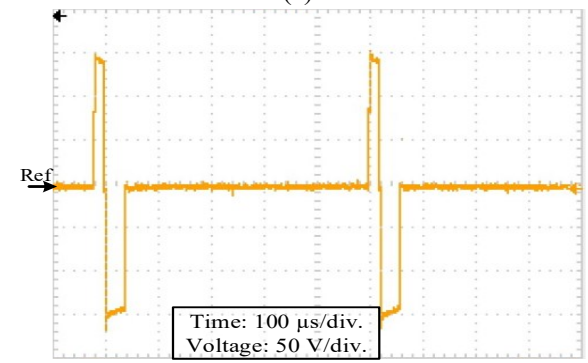

(b)

Fig. 18. Experimental results for UPG asymmetrical rectangular pulses: (a) bipolar with positive $t_{m}=40 \mu \mathrm{s}$ and negative $t_{m}=20 \mu \mathrm{s}$ and (b) combined null durations with positive $t_{m}=20 \mu \mathrm{s}$ and negative $t_{m}=40 \mu \mathrm{s}$.

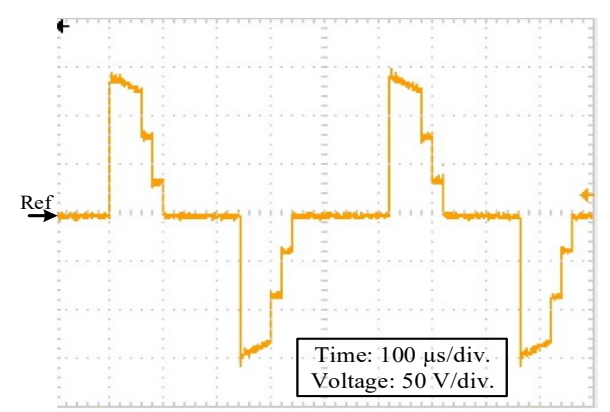

(a)

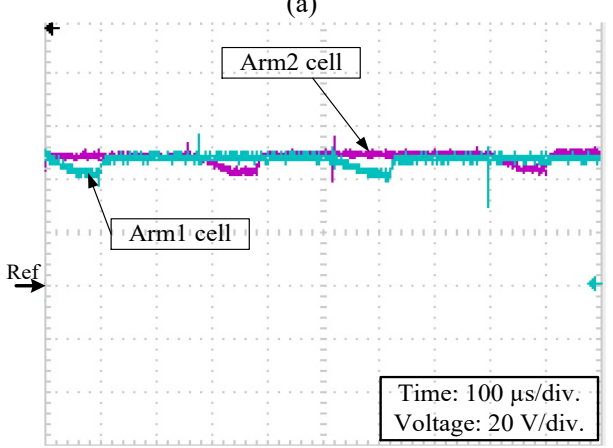

(b)

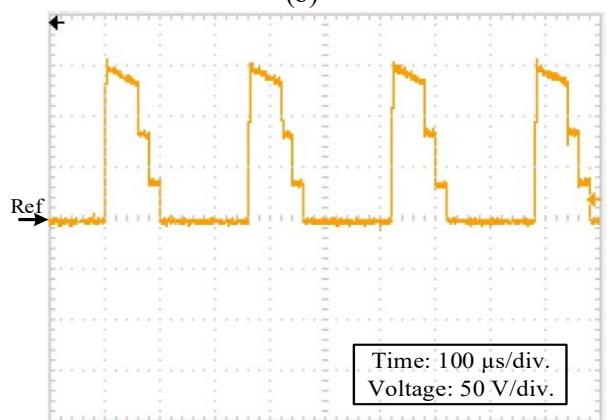

(c)

Fig. 19. Experimental results for UPG exponential pulses with $t_{x}=20 \mu \mathrm{s}$ and $t_{m}=40 \mu \mathrm{s}$ : (a) bipolar (b) a cell-capacitor voltage in the 2 transition arms, and (c) monopolar.

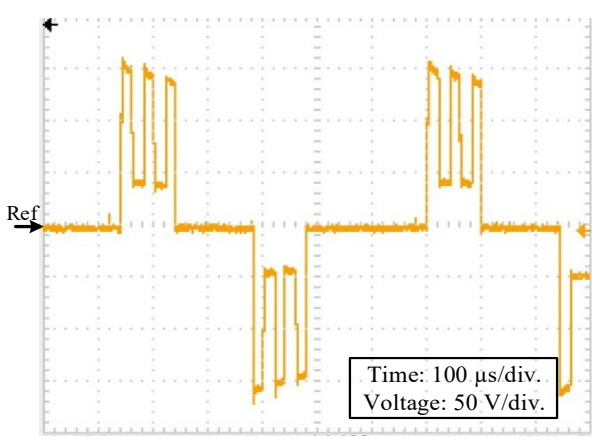

(a)

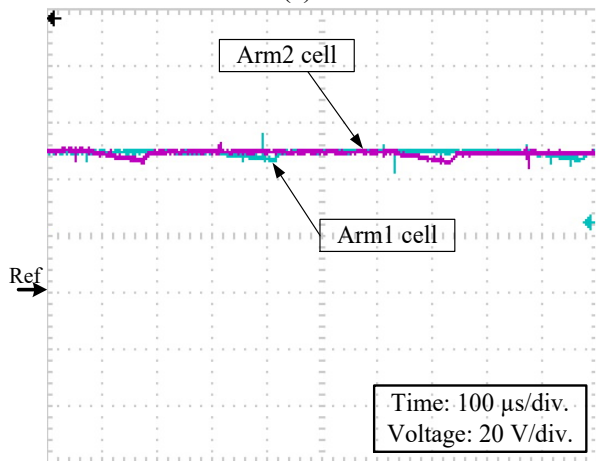

(b)

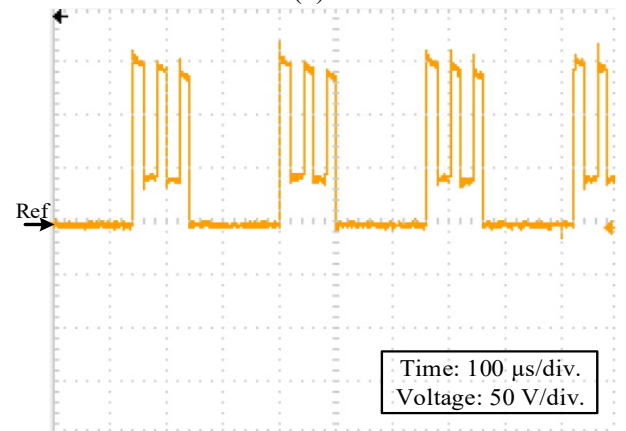

(c)

Fig. 20. Experimental results for UPG combined wide and narrow pulses with $m=2$ and $t_{x}=20 \mu \mathrm{s}$ : (a) bipolar (b) a cell-capacitor voltage in the 2 transition arms, and (c) monopolar.

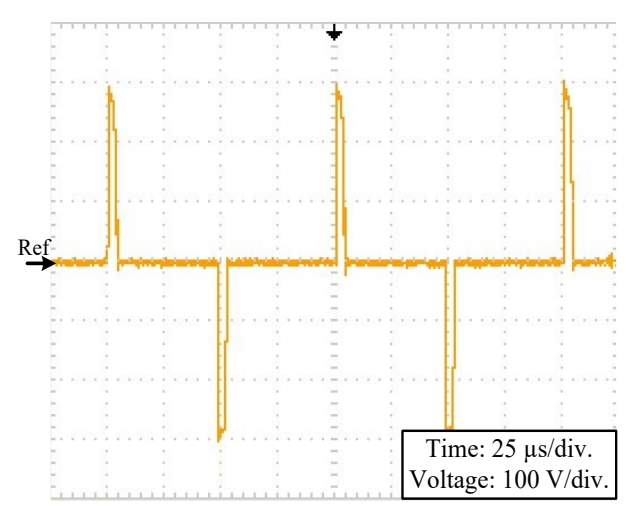

Fig. 21. Experimental results for UPG bipolar rectangular pulses with $t_{m}=$ $4 \mu \mathrm{s}$, repetition frequency of $10 \mathrm{kHz}$ and voltage of $0.6 \mathrm{kV}$ peak-peak. 


\section{TOPOLOGY VARIATIONS AND LIMITATIONS}

There are UPG topology variations, dependent on the application requirements.

Arm inductance: The arm inductor $L_{a}$ is small and may be accounted for by the inherent internal wiring and connection of the cells. Clamping the inductors with freewheel diodes is possible but the low voltage of the forward biased diode may result in an excessively long $L / R$ reset time constant, which will limit the upper operating frequency. The energy of remaining unclamped stray inductance, rings with the cell capacitors.

Elimination of bi-state arm diodes: MMC cell-capacitor recharging involves an $L C R$ oscillation, where if under damped, the current alternately reverses. The damping losses are independent of the circuit $Q$, thus critical damping incurs the lowest stresses, with an acceptable settling time. As such, without current reversal, the bi-state arm diodes across the IGBTs are redundant. To maximize power transfer, any (added and/or exiting) resistance should be in the bi-state arm. Both MMC arm series inductors can be moved to their associated series bi-state arm.

Bi-state arm switches: The switching properties of the bistate arm devices can be much slower than those necessary for the transition arms (HB-MMC arms). Also, because their inter dc rail state transitions are with zero current, they can be higher voltage (consequently slower) rated devices, used near their voltage limit. Thus the number of bi-state arm series connected devices can be much less than $N$, the number MMC cells. The tradeoff of higher voltage devices is higher OFFstate leakage current, so the parallel connected static voltage sharing resistance is decreased.

The input supply voltage: The proposed UPG topology for generating the HV pulses can be supplied from a dc-dc boosting stage. Additionally, the use of a 12-pulse ac-dc thyristor half-controlled converter to supply the UPG offers soft start up and shut down.

Finally, the ability of the converter to generate high repetition rate pulses only depend on the speed of selected controller in executing the control software instructions, such that the total software execution time is less than the required pulse repetition time. For high repetition rates and/or short pulse durations, the utilisation of fast (short turn ON delays) semi-conductor switches is mandatory.

\section{CONCLUSION}

This paper presented a universal HV pulse-waveform generator, UPG, which emulates the dominate HV pulsewaveforms in PEF electroporation applications. The proposed UPG topology is based on transition arms of series connected HB-MMC cells, which has been utilized for quasi two-level voltage generation in DAB dc-dc converters for HVDC transmission applications. In the UPG, two transition arms are used for negative and positive voltage pulse generation along with two bi-state arms which allow charging of the transition arms capacitors. The proposed UPG generates multilevel pulses that has low $d v / d t$ which allow reduction of the electromagnetic interference (EMI) generated by the converter. The controller software-algorithm allows manipulation of the multilevel pulse-waveform characteristics to generate rectangular, exponential and combined narrow and wide pulses. The UPG can generate both bipolar and monopolar HV pulse-waveforms of micro-second pulse durations with controllable voltage magnitude, pulse duration and pulse repetition frequency characteristics. Therefore, the proposed topology provides flexibility via its controller software-algorithm, along with hardware modularity, scalability, and redundancy. The HB-MMC cell-capacitors in the transition arms provide a controllable energy source which charges from the dc input supply and discharges across the load. The bi-state arms allow charging of the HB-MMC cellcapacitors in the transition arms from the dc input supply. Unlike the conventional HB-MMC used in HVDC transmission applications, the UPG converter has reduced footprint, weight and cost by utilizing small cell-capacitances in the HB-MMC and employing bi-state arms. The cellcapacitor voltages are maintained around $V_{S} / N$ by measuring their individual voltages, continuously, and applying a sorting and rotating algorithm. Simulations and experimental results confirm the viability of the proposed UPG, which promotes it for PEF application.

\section{ACKNOWLEDGEMENT}

This work was supported by the Qatar National Research Fund (a member of the Qatar Foundation) under NPRP Grant (7-203-2-097). The statements made herein are solely the responsibility of the authors.

\section{REFERENCES}

[1] S. Y. Tseng, T. F. Wu, and M. W. Wu, "Bipolar narrow-pulse generator with energy-recovery feature for liquid-food sterilization," IEEE Trans. Ind. Electron., vol. 55, pp. 123-132, 2008.

[2] K. H. Schoenbach, F. E. Peterkin, R. W. Alden, and S. J. Beebe, "The effect of pulsed electric fields on biological cells: experiments and applications," IEEE Trans. Plasma Sci., vol. 25, pp. 284-292, 1997.

[3] M. Rebersek and D. Miklavcic, "Advantages and disadvantages of different concepts of electroporation pulse generation," Automatika-Journal for Control, Measurement, Electronics, Computing and Communications, vol. 52, no. 1, 2011.

[4] K. H. Schoenbach, S. Katsuki, R. H. Stark, E. S. Buescher, and S. J. Beebe, "Bioelectrics-new applications for pulsed power technology," IEEE Trans. Plasma Sci., vol. 30, pp. 293-300, 2002.

[5] A. Sheikholeslami and J. Adabi, "High-voltage pulsed power supply to generate wide pulses combined with narrow pulses," IEEE Trans. Plasma Sci., vol. 42, no. 7, pp. 1894-1901, Jul. 2014.

[6] A. Abou-Ghazala, S. Katsuki, K. H. Schoenbach, F. C. Dobbs, and K. R. Moreira, "Bacterial decontamination of water by means of pulsed-corona discharges," IEEE Trans. Plasma Sci., vol. 30, pp. 1449-1453, 2002.

[7] H. Bluhm, Pulsed power systems: principles and applications, Berlin, Springer, 2006. 
[8] J. Raso and V. Heinz, Pulsed electric fields technology for the food industry: fundamentals and applications, New York, London, Springer, 2006.

[9] Q. Bai-Lin, Z. Qinghua, G. V. Barbosa-Canovas, B. G. Swanson, and P. D. Pedrow, "Inactivation of microorganisms by pulsed electric fields of different voltage waveforms," IEEE Trans. Dielect. Elect. Insulation, vol. 1, no. 6, pp. 1047-1057, 1994.

[10] W. Tsai-Fu, T. Sheng-Yu, and H. Jin-Chyuan, "Generation of pulsed electric fields for processing microbes," IEEE Trans. Plasma Sci., vol. 32, pp. 1551-1562, 2004.

[11] S. H. Jayaram, "Sterilization of liquid foods by pulsed electric fields," IEEE Electr. Insul. Mag., vol. 16, pp. 17-25, 2000.

[12] M. S. Moonesan and S. H. Jayaram, "Effect of pulse width on medium temperature rise and microbial inactivation under pulsed electric field food treatment," IEEE Trans. Ind. Applicat., vol. 49, pp. 1767-1772, 2013.

[13] H. Shi, Y. Lu, T. Gu, J. Qiu, and K. Liu, "High-voltage pulsewaveform modulator based on solid-state Marx generator," IEEE Trans. Dielectr. Electr. Insul., vol. 22, pp. 1983-1990, 2015.

[14] C. Yao, S. Dong, Y. Zhao, Y. Mi, and C. Li, "A Novel Configuration of Modular Bipolar Pulse Generator Topology Based on Marx Generator With Double Power Charging," IEEE Trans. Plasma Sci., vol. PP, pp. 1-7, 2016.

[15] J. Wu, W. Ding, H. Ren, R. Han, Y. Liu, X. Sun, et al., "A Novel Compact Repetitive Frequency Square-Wave Generator Based on Coaxial Pulse Forming Lines and Coupled Magnetic Switches," IEEE Trans. Plasma Sci., vol. 42, pp. 1714-1720, 2014.

[16] L. Li, K. Liu, and J. Qiu, "Repetitive high voltage rectangular waveform pulse adder for pulsed discharge of capacitive load," IEEE Trans. Dielectr. Electr. Insul., vol. 20, pp. 1218-1223, 2013.

[17] E. Veilleux, B. T. Ooi, and P. W. Lehn, "Marx dc-dc converter for high-power application," Power Electronics, IET, vol. 6, no. 9, pp. 1733-1741, 2013.

[18] T. Sakamoto, A. Nami, M. Akiyama, and H. Akiyama, "A Repetitive Solid State Marx-Type Pulsed Power Generator Using Multistage Switch-Capacitor Cells," IEEE Trans. Plasma Sci., vol. 40, no. 10, pp. 2316-2321, 2012.

[19] M. Rezanejad, A. Sheikholeslami, and J. Adabi, "Modular switched capacitor voltage multiplier topology for pulsed power supply," IEEE Trans. Dielect. Elect. Insulation, vol. 21, pp. 635-643, Apr. 2014.

[20] S. Zabihi, F. Zare, G. Ledwich, A. Ghosh, and H. Akiyama, "A new pulsed power supply topology based on positive buck-boost converters concept," IEEE Trans. Dielect. Elect. Insulation, vol. 17, no. 6, pp. 1901-1911, Dec. 2010.

[21] A. Elserougi, A. M. Massoud, and S. Ahmed, "A Modular HighVoltage Pulse-Generator with Sequential Charging for Water Treatment Applications," IEEE Trans. Ind. Electron., vol. 63, no. 12, pp. 7898-7907, 2016.

[22] L. L. Rocha, J. F. Silva, and L. M. Redondo, "Multilevel highvoltage pulse generation based on a new modular solid-state switch," IEEE Trans. Plasma Sci., vol. 42, no. 10, pp. 2956-2961, Oct. 2014.

[23] L. L. Rocha, J. F. Silva, and L. M. Redondo, "Seven-Level Unipolar/Bipolar Pulsed Power Generator," IEEE Trans. Plasma Sci., vol. 44, no. 10, pp. 2060-2064, 2016.

[24] L. M. Redondo and J. F. Silva, "Flyback versus forward switching power supply topologies for unipolar pulsed-power applications," IEEE Trans. Plasma Sci., vol. 37, no. 1, pp. 171-178, Jan. 2009.

[25] A. Elserougi, A. M. Massoud, A. M. Ibrahim, and S. Ahmed, "A high voltage pulse-generator based on DC-to-DC converters and capacitor-diode voltage multipliers for water treatment applications," IEEE Trans. Dielectr. Electr. Insul., vol. 22, pp. 3290-3298, 2015.
[26] I. A. Gowaid, G. P. Adam, B. W. Williams, A. M. Massoud, and S. Ahmed, "The transition arm multilevel converter -A concept for medium and high voltage dc-dc transformers," in Industrial Technology (ICIT), 2015 IEEE International Conference on, 2015, pp. 3099-3104.

[27] F. Zare, "EMI issues in modern power electronic systems," The IEEE EMC Society Newsletters, pp. 53-58, 2009.

[28] G. P. Adam, O. Anaya-Lara, G. M. Burt, D. Telford, B. W. Williams, and J. R. McDonald, "Modular multilevel inverter: Pulse width modulation and capacitor balancing technique," Power Electron. IET, vol. 3, pp. 702-715, 2010.

[29] A. Nami, L. Jiaqi, F. Dijkhuizen, and G. D. Demetriades, "Modular multilevel converters for HVDC applications: Review on converter cells and functionalities," IEEE Trans. Power Electron., vol. 30, no. 1, pp. 18-36, Jan. 2015.

[30] M. A. Elgenedy, A. Darwish, S. Ahmed, and B. W. Williams, "A modular multilevel-based high-voltage pulse generator for water disinfection applications," IEEE Trans. Plasma Sci., vol. 44, pp. 2893-2900, 2016.

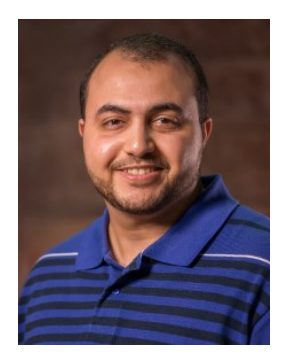

Mohamed A. Elgenedy (S'15) received the B.Sc. (with first-class honors) and M.Sc. degrees in Electrical Engineering from Alexandria University, Egypt in 2007 and 2010 respectively. Currently he is working toward the Ph.D. degree at the University of Strathclyde, Glasgow, U.K. He is also an assistant lecturer with the Electrical Engineering Department, Faculty of Engineering, Alexandria University.

In 2012, he was with Spiretronic LLC, Houston, TX, USA, as a Research Engineer. From 2013 to 2014, he was a Research Associate at Texas A\&M University at Qatar. His research interests include high power electronics, electric machine drives, energy conversion, and renewable energy.

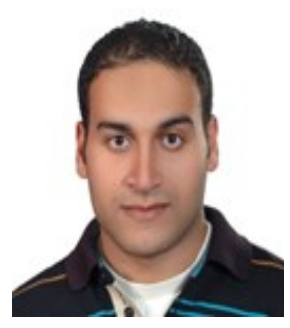

Ahmed Darwish received the B.Sc. and M.Sc. degrees in electrical engineering from the Faculty of Engineering, Alexandria University, Alexandria, Egypt, in 2008 and 2012, respectively, and the Ph.D. degree in electric engineering from the Department of Electronic and Electrical Engineering, University of Strathclyde, Glasgow, U.K., in 2015.

From 2009 to 2012, he was a Research Assistant at Texas A\&M University at Qatar, Doha, Qatar. He is currently a Research Associate with PEDEC Group at the University of Strathclyde. His research interests include dc-dc converters, multilevel converters, electric machines, digital control of power electronic systems, energy conversion, renewable energy, and power quality.

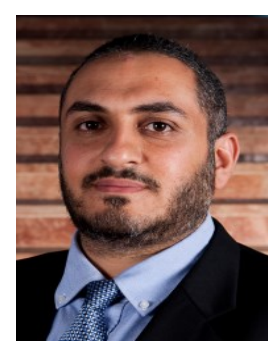

Shehab Ahmed (SM'12) was born in Kuwait City, Kuwait in July 1976. He received the B.Sc. degree in Electrical Engineering from Alexandria University, Alexandria, Egypt, in 1999; the M.Sc. and Ph.D. degrees from the Department of Electrical \& Computer Engineering, Texas A\&M University, College Station, TX in 2000 and 2007, respectively.

From 2001 to 2007, he was with Schlumberger Technology Corporation working on downhole mechatronic systems. He is currently an Assoicate Professor with Texas A\&M University at Qatar, Doha, Qatar. His research interests include mechatronics, solid-state power conversion, electric machines, and drives. 


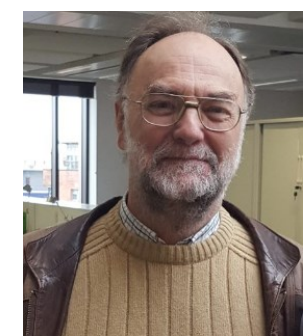

Barry W. Williams received the M.Eng.Sc. degree from the University of Adelaide, Adelaide, Australia, in 1978, and the Ph.D. degree from Cambridge University, Cambridge, U.K., in 1980. After seven years as a Lecturer at Imperial College, University of London, London, U.K., he was appointed to a Chair of Electrical Engineering at Heriot-Watt University, Edinburgh, U.K, in 1986.

He is currently a Professor at the University of Strathclyde, Glasgow, U.K. His teaching covers power electronics (in which he has a free internet text) and drive systems. His research activities include power semiconductor modeling and protection, converter topologies, soft switching techniques, and application of ASICs and microprocessors to industrial electronics. 